\title{
Toll Like Receptor 4 (TLR4) and p65 Nuclear Factor Kappa B (NF-kB) Expression in Monocyte Cell of Children with Steroid Resistant Nephrotic Syndrome
}

\author{
Tikto Wahyono1, Krisni Subandiyah², Loeki Enggar Fitri ${ }^{3 *}$, Agustina Tri Endharti ${ }^{3}$ \\ ${ }^{1}$ Magister Program in Biomedical Science, University of Brawijaya \\ ${ }^{2}$ Department of Pediatric, dr. Saiful Anwar Hospital, Malang Indonesia \\ ${ }^{3}$ Laboratory of Parasitology, Faculty of Medicine University of Brawijaya, Malang Indonesia
}

\begin{abstract}
This research aimed to prove the difference of TLR4 and p65NF-kB subunit expression between children with steroid-sensitive nephrotic syndrome (SSNS) and those with steroid-resistent nephrotic syndrome (SRNS) and to find out the correlation between expression of TLR4 and p65NF-kB on children with SRNS. Twenty three patients of idiopathic nephrotic syndrome patients (INS) were enrolled in this study and classified into two groups-those with SSNS (11 patients) and SRNS (12 patients). Peripheral Blood Mononuclear Cells (PBMC) isolation was performed, taken from $5 \mathrm{ml}$ patients' blood samples, followed by monocyte isolation of PMBC using monocyte culture. Examination of TLR4 and p65NF-kB expression from monocyte's cells culture was performed using flow cytometry. The result showed that the differences of TLR4 expression between SSNS and SRNS was significant $(\mathrm{p}=0.012)$, The differences of $\mathrm{p} 65 \mathrm{NF}-\mathrm{kB}$ expression between SSNS and SRNS showed an insignificant correlation $(\mathrm{p}=0.880)$. Pearson correlation test between the expression of TLR4 and p65NF-kB showed no significant correlation $(\mathrm{p}=0.472)$, while Spearman correlation test to see the relationship between expression of TLR4 and SRNS produced correlation value of 0.512 and its importance $\mathrm{p}$ value was $0.013(\mathrm{p}<0.05)$. There is a significant difference of TLR4 expression between SRNS and SSNS and there is also a significant correlation between expression of TLR4 and SRNS, that proved TLR4 has an important role in steroid resistance of nephrotic syndrome.
\end{abstract}

Keywords: INS, SSNS, SRNS, TLR4 expression, p65 NF-kB expression

\section{INTRODUCTION}

Nephrotic syndrome (NS) is a group of clinical symptom consisting of massive proteinuria, hypoalbuminemia, oedema and is also accompanied by hypercholesterolemia. In some cases, some microscopic hematuria symptoms, hypertension, and temporarily increasing urea level as well as creatinine are also seen. Nephrotic Syndrome is the most frequently renal disease on children $[1,2,3]$. Idiophatic nepro-

\footnotetext{
${ }^{*}$ Corresponding author:

Loeki Enggar FitriLaboratory of Parasitology,

Faculty of Medicine, University of Brawijaya,

Malang-Indonesia

E-mail: lukief@ub.ac.id
}

-tic syndrome (INS) occupies the highest number of cases on children aged 2-6. It is reported that there are 251 children aged 3-15 suffering from nephrotic syndrome, $85 \%$ of which is idiopathic nephrotic syndrome, while $15 \%$ is congenital and secondary nephrotic syndrome patients [4]. The highest histophatologic description of idiopathic nephrotic syndrome on children is a minimal change disease (MCD) accounting for $80 \%$, while focal segmental glomerulosclerosis (FSGS) accounts for 7-8 \%, mesangial proliferative diffuse (MPD) accounts for 2-5\%, membranoproliferative glomerulonephritis makes up 4-6\%, and membranous glomerulonephritis accounts for 1 $5 \%$. 
Based on the reports on treatment using steroid, nephrotic syndrome is divided into two, namely steroid-sensitive nephrotic syndrome (SSNS) and steroid-resistant nephrotic syndrome (SRNS). In the former group, there is improved clinical conditions (remission) within 4 weeks of initial therapy while the latter shows no improved clinical states $[5,6]$. In the initial corticosteroid treatment, most MCD (94\%) undergoes total remission (responsive), while in FSGS it accounts for $80-85 \%$, irresponsive. Generally, SSNS incidence level is nearly $80-90 \%$, while SRNS comprises $10-20 \%[5,7]$.

The most important factor in determining prognosis on children with nephrotic syndrome is their response to steroid (Glucocorticoid) treatment. Glucocorticoid is one of the antiinflammatory molecules that works by binding to glucocorticoid receptor- $\alpha \quad(\mathrm{GR}-\alpha)$ through transcription factor mediator mechanism. Glucocorticoid does not bind to glucocorticoid receptor- $\beta$ (GR- $\beta)$ or transactivation target gene (8). The role of glucocorticoid anti-inflammatory effect is affected by its capability to inhibit the activities of two transcription factors which are activator protein-1 (AP-1) and nuclear factor-kappa B (NF- $x$ B) [9]. Nuclear factor-kappa B is a heterodimer of p50 and p65 subunit as an inactive form in which in cytoplasm it binds to inhibitor kappa-B (I-xB). After translocating into nucleus, heterodimer $\mathrm{NF}-x \mathrm{~B}$ will be bound to specific DNA and activates transcription of cytokine gene that has a role in immune response and inflammation [10,11]. Currently, there have still been many controversial research findings related to expression of Nfkb in PBMC of INS. Aviles et al., (2004) showed the decreased expression of p 65NFkB subunit in lymphocyte cell of the SRNS while the different finding was illustrated by Audred et al., (2012) in which there was an increased expression of NF-kB of CD4+ lymphocyte cell on INS $[12,13]$.

Until recently, etiopathogenesis of nephrotic syndrome in children is still unclear. There are, however two main factors, an immunological dysfunction and genetic factor. Research regarding the role of Toll like receptor (TLR) in various diseases due to immunological defect is now developing. Toll like receptor is an important component of innate immunity, having an important role in the early detection of pathogen associated molecular patterns (PAMPs) and then activates an adaptive immune response. Toll like receptor is expressed from various types of cells of body immunity, especially those involved in the first line of body defence toward pathogen [14]. In nephrotic syndrome pathogenesis, there is new evidence showing the activation function of nephrotic syndrome on innate immune via TLR initiated by microbial products that can directly affect podocyte of the kidney. In addition, microbial products also indirectly affect podocyte through antigen presenting cell (APC). The activated APC cells will secrete nuclear factor kappa B (NF-kB); a transcription factor directly affecting $\mathrm{TH} 2$ adaptive immune response and directly increases expression of CD80 in podocyte. However, research related to the involvement of TLR on nephrotic syndrome has not been yet much conducted [15]. This research will try to find out the role of TLR4 and $\mathrm{p} 65 \mathrm{NFkB}$ subunit in relation to the occurence of idiopatic nephrotic syndrom.

\section{MATERIALS AND METHODS}

\section{Ethics}

This study has got research ethical clearance, issued by Health Research Ethics Commision from dr. Saiful Anwar General Hospital, Malang, East Java, Indonesia.

\section{Research subjects}

The research subjects were children that diagnosed as idiophatic steroid-resistant nephrotic syndrome and idiophatic steroidsensitive nephrotic syndrome. The criteria of the former group, idiophatic steroid-resistant nephrotic syndrome in which remission does not occur using full dose prednison administration (full dose) $2 \mathrm{mg} / \mathrm{kgBW} /$ day for 4 weeks. While the criteria of idiophatic steroid-sensitive nephrotic syndrome is nephrotic syndrome that having remission using full dose prednison administration $2 \mathrm{mg} / \mathrm{kgBW} /$ day for 4 weeks. Remission is negative proteinuria or trace (proteinuria $<4 \mathrm{mg} / \mathrm{m} 2 \mathrm{LPB} / \mathrm{jam}$ ) is performed in three respective days in a week. Inclusive criteria of research subjects are patients with idiopathic nephrotic syndrome, aged between 1 and 14 and the patient's family permits the child to participate in this study after informed consent is notified. Exclusive criteria of study subjects include secondary nephrotic syndrome which is a 
nephrotic syndrome caused by external renal factor such as those exposed to chemicals substances/drug, those derived from systemic diseases such as lupus eritematous, purpura Henoch Schonlein, some infectious diseases such as malaria, hepatitis and patients with congenital infantile nephrotic syndrome which is nephrotic syndrome that starts to show its symptoms in the patient's early life years.

\section{Flow cytometry examination.}

The study started with blood withdrawal amounting $5 \mathrm{ml}$, given EDTA, which was then followed by isolation of PBMC by Ficoll Hypaque (Biomedicals USA, cat\#50494, $1.077 \mathrm{~g} / \mathrm{ml})$. Analysis of flow cytometry was performed using Fluorescence Activated Cell Sorter (FACS Calibur). The first analysis step was performing gating strategies on CD14 monocyte cell (anti-human CD14-PerCP/Cy5.5 antibody cat\#325622, Biolegend, USA, which was then followed by analysis of TLR4 expression on cell membranes, labeled with anti human TLR 4-PE monoclonal antibody cat 312806, Biolegend, USA. The intracellular/cytoplasmic p65 NF-kB was determined by staining labeled with anti NFkBp65-FITC polyclonal human antibody (cat b50465R, Bioss). Percentage of TLR4 and p65 NF-
$\mathrm{kB}$ expression was analyzed using cell questpro software.

\section{Statistical analysis}

Shapiro-Wilk test was used to test the distribution of normal data, while test of homogeneous data was performed using Levene test. Comparation variables of two groups (SSNS and SRNS) were analyzed using unpaired t-test for TLR4 and Mann-Whitney test for p65 NF$\mathrm{kB}$. Correlation between groups was tested using Pearson correlation test. It is significant if $\mathrm{p}$ value <0.05. All data was analyzed using Statistical Package for the Social Sciences (SPSS 15) for Windows.

\section{RESULTS AND DISCUSSION}

\section{Subjects Characteristic}

This research used cross-sectional design with consecutive sampling. There were 23 patients of idiopathic nephrotic syndrome divided into two groups which were SSNS, accounting for 11 patients, and SRNS patients, which were 12 patients. The basic characteristics of each group are presented in table 1.

Table 1. Characteristic of group of sensitive steroid and resistant-steroid nephrotic syndrome.

\begin{tabular}{lcccc}
\hline Characteristic & $\begin{array}{c}\text { SSNS } \\
(\mathrm{n}=11)\end{array}$ & $\begin{array}{c}\text { SRNS } \\
(\mathrm{n}=12)\end{array}$ & Total $(\mathrm{n}=23)$ & P \\
\hline $\begin{array}{l}\text { Gender } \\
\text { Male }\end{array}$ & $5(45 \%)$ & $11(91.7 \%)$ & $16(69.6 \%)$ & \\
$\quad$ Female & $6(55 \%)$ & $1(8.3 \%)$ & $7(30.4 \%)$ & \\
Age & & & & 0.892 \\
$\quad \leq 2$ year & $1(9.1 \%)$ & $0(0 \%)$ & $1(4.4 \%)$ & \\
$2-6$ year & $3(27.3 \%)$ & $6(50 \%)$ & $9(39.1 \%)$ & \\
$\geq 6$ year & $7(63.6 \%)$ & $6(50 \%)$ & $13(56.5 \%)$ & \\
Nutritional status & & & & 0.045 \\
Good status & $9(81.8 \%)$ & $5(41.7 \%)$ & $14(60.9 \%)$ & \\
Undernourished & $2(18.2 \%)$ & $6(50 \%)$ & $8(34.8 \%)$ & \\
Malnourished & 0 & $1(8.3 \%)$ & $1(4.3 \%)$ & \\
\hline
\end{tabular}


The average age of the study subject is $7.59 \pm$ 3.52 years and 6 years old or more were the most prevalence aged $(56.5 \%)$. From 12 patients diagnosed with SRNS, $8.3 \%$ had a malnourished status, $50 \%$ had undernourished status and $41.7 \%$ had good nutritional status, and from 11 patients diagnosed with SSNS, $18.2 \%$ had undernourished status and $81.8 \%$ had good nutritional status.

\section{The difference on TLR4 expression between SSNS and SRNS}

Based on the normality test using SaphiroWilk, it was noted that variable data to be tested, expression of TLR4, indicated a significance result of $0.620 \quad(p>0.05)$. It can then be concluded that variable data spreads TLR4, following standard distribution, allowing the study with t-test.

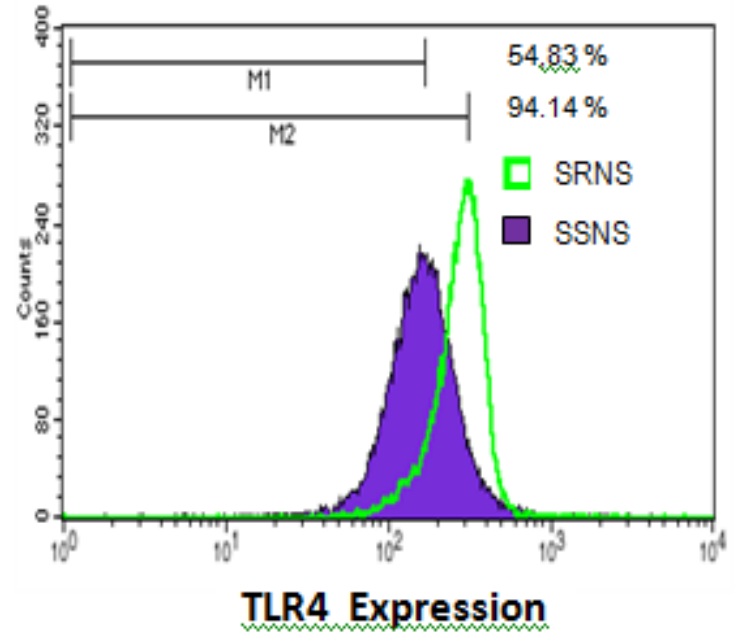

A.

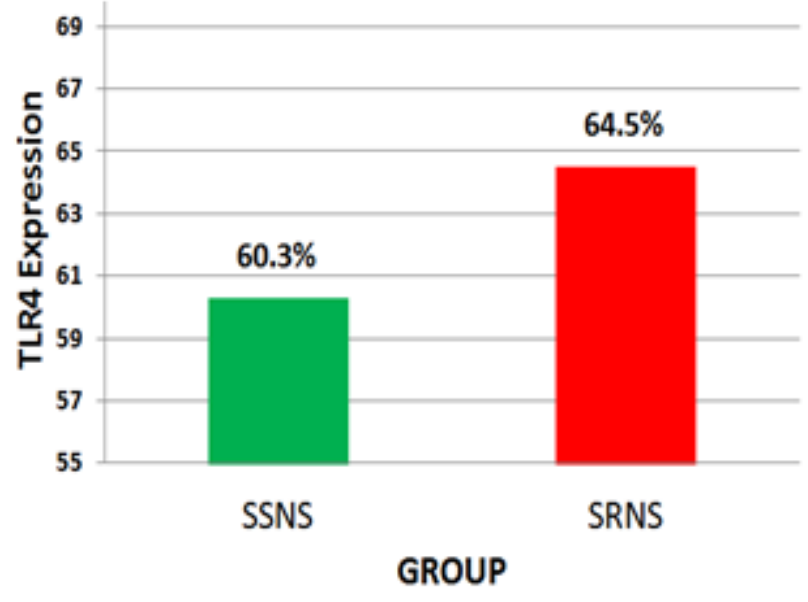

B.

Figure 1. The difference expressions on TLR4 between SRNS and SSNS. A. Representative histograms are showing expression of TLR4 in SRNS group (M2 $=94.14 \%$ ) higher than SSNS group (M1 $=54.83 \%$ ). B. Mean data of TLR4 expression (\%) from 11 samples in SSNS group and 12 samples in SRNS group, data shows a significant difference in the expression of TLR4 in SRNS group compared to SSNS group, *p value $0.012(\mathrm{p}<0.05)$.

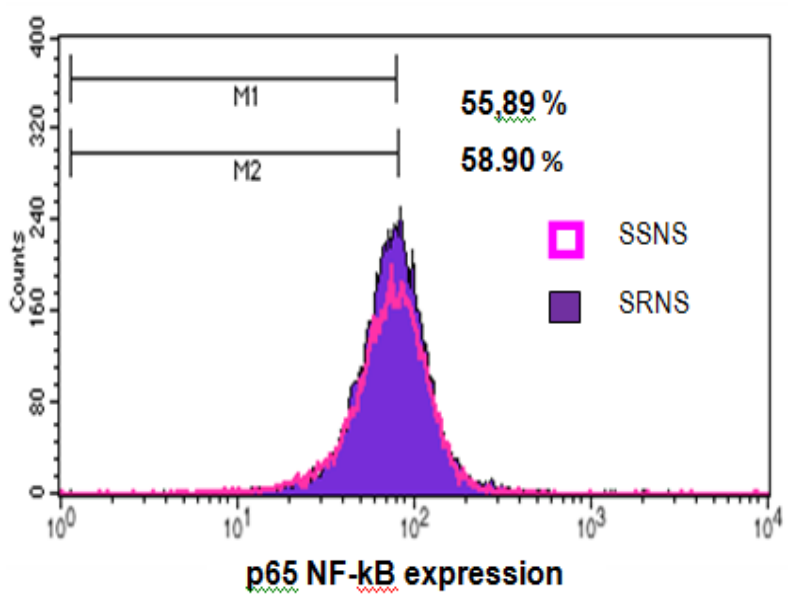

A.

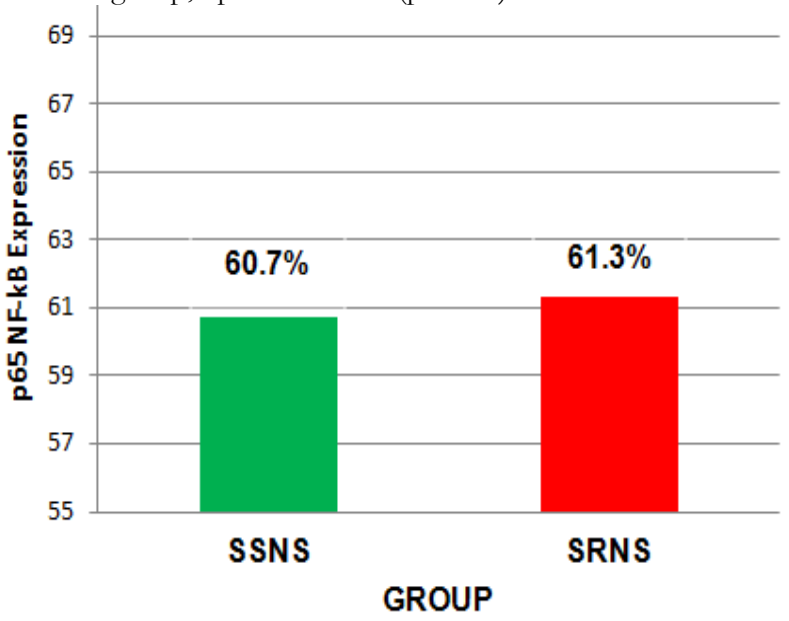

B.

Figure 2. The differences expression of $\mathrm{p} 65 \mathrm{NFkB}$ subunit between SRNS and SSNS. A. Representative histograms of p65NF-kB expression showed almost similar data between SRNS group (M2 $=58.90 \%)$ compared to SSNS group $(\mathrm{M} 1=55.89 \%)$. B. Mean data of p65NF-kB expression (\%) from 11 samples in SSNS group and 12 samples in SRNS group, the data shows no significant difference in the expression of p65 NF-kB of SRNS group compared to SSNS, p value 0.551 ( $\mathrm{p}>0.05$ ). 
Before performing unpaired t-test, the result of homogeneous analysis of various data needed to be found out. The analysis result of different data for TLR4 expression with Levene test showed a significance level of 0.318 ( $p>0.05)$. Then it can be summed up that data on patients' TLR4 expression is homogeneous, allowing the analysis of independent $\mathrm{t}$-test with the assumption of homogeneous data variation (equal variance assumed). The difference expression of TLR4 between SSNS and SRNS patients showed t value of 2.742 with its importance $p$ value of 0.012 , smaller than alpha 0.05. It can then be concluded that there was a significant difference of TLR4 expression between patients with SRNS and SSNS. The difference is depicted in which the average expression of TLR4 expression of SRNS patients are likely to be higher $($ mean $=64.5 \%$ ) than that of SSNS patients ( mean $=60.3 \%$ ).

\section{The difference of expression on p65NF- $k B$ between SSNS and SRNS}

Based on the normality test using SaphiroWilk, it was noted that variable data to be tested, expression of $\mathrm{p} 65 \mathrm{NF}-\mathrm{kB}$, indicated a significance result of $0.027 \quad(\mathrm{p}<0.05)$. It can then be concluded that variable data spreads p $65 \mathrm{NF}-\mathrm{kB}$ in abnormal distribution. From the test of Mann Whitney, the difference expression of p 65 NF-kB of SSNS and SRNS group, its importance value (p) of 0.880 , higher than alpha 0.05. It can then be concluded that there was an insignificant difference of expression of p65NF-kB subunit between SRNS and SSNS patients despite a higher average value of $\mathrm{p} 65 \mathrm{NF}-\mathrm{kB}$ subunit expression of SRNS patients (mean $=61.3 \%$ ) than that of patients with SSNS (mean $=60.8 \%$ ).

\section{The correlation between expression of TLR4 and p65NF-kB Subunit.}

Based on the correlation value obtained from Pearson Test, it was noted that the correlation between the expression of TLR4 and the expression of $\mathrm{p} 65 \mathrm{NF}-\mathrm{kB}$ subunit has a correlation coefficient value of 0.158 with its significance value of $0.472(\mathrm{p}>0.05)$. It can then be summarized that there was an insignificant correlation between the expression of TLR4 and p65NF-kB.

\section{The correlation between expression of TLR4 and SRNS.}

Based on the correlation test using Spearman correlation, it was noted that the correlation between expression of TLR4 and SRNS had a correlation coefficient value of 0.512 with its significant value of $0.013(\mathrm{p}<0.05)$, so that it can be summarized that there was a significant correlation between expression of TLR4 and SRNS. The higher TLR4 expression, the higher occurrence of SRNS (due to its positive correlation coefficient), while the lower expression of TLR4, followed by the lower occurrence of SRNS.

\section{The correlation between expression of p65NF-kB and SRNS.}

Based on correlation test using Spearman test, it was noted that the correlation between expression of p65NF-kB and SRNS has correlation coefficient value of 0.039 , where the significant value is 0.858 ( $\mathrm{p}>0.05)$, so that it can be concluded that there was an insignificant correlation between expression of p65NF-kB and SRNS.

One of the clinical features of INS is the recurrence after viral and bacterial infection especially on children. The phenomenon may be related to dysfunctional innate body immunity. This innate immunity response occurs several hours after infection and depends on the introduction of microbial products by specific receptors which are TLRs, which is expressed by APC, macrophage, neutrophil, natural killer (NK) cells, epithelial and endothelial cells. Toll Like Receptor (TLR) involvement triggers cascade signal involving MyD88, IRAK and TRAF6, resulting in activation of NF-kB and AP-1 pathways, which then induces inflammatory gene activation such as TNF $\alpha$, IL1, IL6 and IL8 [19]. Nuclear Factor Kappa Beta (NF-kB) signal activation on non-cell $\mathrm{T}$ population during INS relapse indicates the involvement of innate immunity cells in this process [20]. This hypothesis is mostly supported by data showing upregulation of many genes recruited in innate immunity response such as regulated on activation, normal $\mathrm{T}$ cell expressed and secreted (RANTES), TNF receptor associated factor 6 (TRAF6), IL1, and IFN $\alpha \mathrm{R}$ [21]. 
This study notes an insignificant difference expression of p $65 \mathrm{NF}-\mathrm{kB}$ subunit between SSNS and SRNS groups despite a higher average value of $\mathrm{p} 65 \mathrm{NF}-\mathrm{kB}$ subunit on SRNS patients $($ mean $=$ $61.3 \%$ ) than SSNS patients (mean $=60.7 \%$ ). Some research shows different results of NF-kB expression on PBMC nephrotic syndrome patients. Research conducted by Aviles et al. (2004) showed that there was a decrease of p65NFkB subunit expression on SRNS patient's lymphocytes. Corebima et al. (2010) indicated an insignificant difference of $\mathrm{p} 65 \mathrm{NF}-\mathrm{kB}$ subunit expression between SSNS and SRNS groups, but there is an increased of $\mathrm{p} 65 \mathrm{NF}-\mathrm{kB}$ subunit activity on SRNS. On the other hand, research conducted by Krisni, (2012) found that p65NF$\mathrm{kB}$ expression on SRNS is highest compared to SSNS and control. Moreoever the same result is also indicated by Audrad et al. (2012) which found the increased expression of $\mathrm{CD} 4+$ lymphocytes NF-kB on INS who undergo a relapse $[12,13,23,24]$. A quick relapse on INS, as a result, of immunogen exposure supported the involvement of innate immunity systems in which signal path of NF-kB plays a central role [25]. Idiopathic nephrotic syndrome relapsed showed an increased expression of p65/p50 heterodimer NF-kB and decreased expression of NF-kB when SSNS patients are administered dexamethasone. The hindrance of NF-kB and AP-1 was an important molecular mechanism of glucocorticoid effect on SSNS therapy [26].

This study also indicates an insignificant correlation between TLR4 and p65NF-kB subunit on SRNS. The result can also result from a relatively fewer number of samples or it may result from the steroid treatment that the patients still underwent, so it affected the expression of those molecules inside monocytes. Some samples of SRNS groups also got treatment using the other immunosuppressant for example cyclophosphamide. In addition, some samples of SRNS groups had undergone medical treatments of steroid more than five years. The other possibilities may result from the exclusion of NF$\mathrm{kB}$ in TLR4 signal path but involved the other transcription factors such as AP-1 or due to the other biased factors, as a result, of immunosuppressant administration such as steroid and cyclophosphamide. However the data still needs further research. This study showed an insignificant correlation between the expression of $\mathrm{p} 65 \mathrm{NF}-\mathrm{kB}$ and SRNS. The phenomenon can also result from the sample study who are still undergoing treatment of immunosuppressant or Cytostatic. The other cause may be due to a fewer samples; thus it is necessary to conduct further research.

\section{CONCLUSIONS}

This study shows an increased expression of TLR4 on SRNS compared to SSNS; however, there is no different expression of p65NF-kB. There is also a significant correlation between expression of TLR4 and SRNS with its significant value of $0.013(p<0.05)$, so there should be further study to examine the role of TLR 4 and p65NF-kB on pathogenesis of steroid resistance on nephrotic syndrome by including more samples and using a different method.

\section{ACKNOWLEDGMENT}

The author thanks to Wahyudha Ngatiril Lady and Surya Kurnia Hayati at the Laboratory of Biomedic Faculty of the Medicine University of Brawijaya, Malang Indonesia for their assistance.

\section{REFERENCES}

1. Bagga A, Mantan M. Nephrotic syndrome in children. Indian J Med Res. 2005;122:13-28.

2. Davin J C, Rutjes N M. Nephrotic Syndrome in Children: From Bench to Treatment. Review Article. Int J Nephrol. 2011; 2011:1-6.

3. UKK Nefrologi Ikatan Dokter Anak Indonesia. Kompendium Nefroliogi Anak. Sindrom Nefrotik Idiopatik. Badan Penerbit Ikatan Dokter Anak Indonesia, Jakarta. pp72-88,2011.

4. Hodson EM, Knight JF, Willis NS, Craig JC. Corticosteroid therapy for nephrotic syndrome in children (Review). Cohcrane Data Base Syst Rev. 2003;(1): CD 001533.

5. UKK Nefrologi Ikatan Dokter Anak Indonesia. Tatalaksana sindrom Nefrotik Idiopatik pada Anak, Badan Penerbit Ikatan Dokter Anak Indonesia, Jakarta. 2008.

6. Yap H K, Cheung W, Murugasu B, Sim S K, Seah C C, Jordan S C. Th1 and Th2 cytokine mRNA profiles in childhood nephrotic syndrome: evidence for increased IL-13 mRNA expression in relapse. J Am Soc Nephrol. 1999;10:529-37.

7. ISKDC. Nephrotic syndrome in children: prediction of histopathology from clinical and laboratory characteristics at time of diagnosis. A 
report of the International Study of Kidney Disease in Children. Kidney Int. 1978;13:159-65.

8. Li LB, Goleva E, Hall CF, Ou LS, Leung DY. Superantigen-induced corticosteroid resistance of human $\mathrm{T}$ cells occurs through activation of the mitogen-activated protein kinase kinase/extracellular signal-regulated kinase (MEK-ERK) pathway. J Allergy Clin Immunol. 2004;114:1059-69.

9. Gonzalez MV, Jimenez B, Berciano MT, Sancho JMG, Caelles C, Lavarga M, Munoz A. Glucocorticoids antagonize AP-1 by inhibiting the activation/phosphorylation of $\mathrm{JNK}$ without affecting its subcellular distribution. J Cell Biol; 2000;150:1199-208.

10. Dutta J, Fan Y, Gupta N, Fan G, Gelinas C. Current insights into the regulation of programmed cell death by $\mathrm{NF}-x \mathrm{~B}$. Oncogene. 2006;25: 6800-16.

11. Perkins ND. Post-translational modifications regulating the activity and function of the nuclear factor kappa B pathway. Oncogene. 2006;25: 6717-30

12. Aviles DH, Vedhaskari M, Manning J, Ochoa AC, Zea AH. Decreased expression of T-cell NF-jB p65 subunit in steroid-resistant nephrotic syndrome. Kidney Int. 2004;66: 60-7.

13. Audrad V, Pawlak A, Candelier M, Lang P, Sahali D. Upregulation of nuclear factor-related kappa B suggests a disorder of transcriptional regulation in minimal change nephritic syndrome. PLos ONE.2012;7: 1-9.

14. Riches C, Blanco P, Rifkin I, Moreau JF, Schaeverbeke T. Role for toll like receptors in autoimmune disease: The example of systemic lupus erythematosus. Joint Bone Spine. 2011;78:124-30

15. Sinha A, Bagga A. Symposium On Pediatric Nephrology. Nephrotic Syndrome. Indian J Pediatr. 2012;10:1-11.

16. Eddy AA, Symons JM. Nephrotic syndrome in childhood. Lancet.2003;362: 629-39.

17. Van den Berg JG, Weening J J. Role of the immune system in the pathogenesis of idiopathic nephrotic syndrome. Clin Sci. 2004;107: 125-36.

18. Ganglof M. Different dimerisation mode for TLR4 upon endosomal acidification ?. Trends Biochem Sci. 2012;37: 92-8

19. Medzhitov R. Toll-like receptors and innate immunity. Nat Rev Immunol. 2001;1:135-45.

20. Sahali D, Pawlak A, Le Gouvello S, Lang P, Valanciuté A, Remy P, Loirat C, Niaudet P, Bensman A, Guellaen G. Transcriptional and post-transcriptional alterations of IkappaBalpha in active minimal-change nephrotic syndrome. J Am Soc Nephrol.2001;12: 1648-58.
21. Sahali D, Pawlak A, Valanciute A, Grimbert P, Lang P, Remy P, Bensman A, Guelllaen G. A novel approach to investigation of the pathogenesis of active minimal- change nephritic syndrome using subtracted cDNA library screening. J Am Soc Nephrol. 2002;13:1238-47.

22. Zhang SY, Audard V, Fan Q, Pawlak A, Lang P, Sahali D. Immunopathogenesis of Idiopathic Nephrotic Syndrome. Contrib Nephrol. 2011;169:94-106.

23. Corebima B. Expression and activation p65 NF$\mathrm{kB}$ in mononuclear cells of steroid-resistant nephrotic syndrome. Dissertation, Medical Faculty of Brawijaya University, Malang, Indonesia, 2010.

24. Krisni S. Gene Expression of GR- $\alpha$ and GR- $\beta$ through the Expression of p $65 \mathrm{NF}-\mathrm{kB}$ subunit and AP-1 response to corticosteroids in idiopathic nephrotic syndrome. Dissertation, Medical faculty of Brawijaya university, Malang, Indonesia, 2012.

25. Karin M, Ben-Neriah Y. Phosphorylation meets ubiquitination: the control of NF- $x \mathrm{~B}$ activity. Annu Rev Immunol. 2000;18:621-63.

26. Cao Y, Greten FR, Karin M, Li Z W. NF-kB in cancer: from innocent by stander to major culprit. Nat Rev Cancer. 2002; 2: 301-10. 